\title{
Addressing barriers to exclusive breast-feeding in low- and middle-income countries: a systematic review and programmatic implications
}

\author{
Justine A Kavle $1,2,3, *$, Elizabeth LaCroix ${ }^{2,3}$, Hallie Dau ${ }^{2,3}$ and Cyril Engmann ${ }^{4,5,6}$ \\ ${ }^{1}$ Maternal and Child Survival Program (MCSP), 1776 Massachusetts Avenue NW, Suite 300, Washington, DC \\ 20036, USA: ${ }^{2}$ PATH, Maternal, Newborn, and Child Health and Nutrition, Washington, DC, USA: ${ }^{3}$ The George \\ Washington University, Milken Institute School of Public Health, Washington, DC, USA: ${ }^{4}$ PATH, Maternal, Newborn, \\ and Child Health and Nutrition, Seattle, WA, USA: ${ }^{5}$ Department of Pediatrics, University of Washington, Seattle, \\ WA, USA: ${ }^{6}$ Department of Global Health, University of Washington, Seattle, WA, USA
}

Submitted 26 April 2017: Final revision received 1 August 2017: Accepted 7 August 2017: First published online 2 October 2017

\begin{abstract}
Objective: Despite numerous global initiatives on breast-feeding, trend data show exclusive breast-feeding (EBF) rates have stagnated over the last two decades. The purpose of the present systematic review was to determine barriers to exclusive breast-feeding in twenty-five low- and middle-income countries and discuss implications for programmes.

Design: A search of Scopus, MEDLINE, CINAHL and PsychINFO was conducted to retrieve studies from January 2000 to October 2015. Using inclusion criteria, we selected both qualitative and quantitative studies that described barriers to EBF. Setting: Low- and middle-income countries.

Subjects: Following application of systematic review criteria, forty-eight articles from fourteen countries were included in the review.

Results: Sixteen barriers to EBF were identified in the review. There is moderate evidence of a negative association between maternal employment and EBF practices. Studies that examined EBF barriers at childbirth and the initial $24 \mathrm{~h}$ postdelivery found strong evidence that caesarean section can impede EBF. There is moderate evidence for early initiation of breast-feeding and likelihood of practising EBF. Breast-feeding problems were commonly reported from crosssectional or observational studies. Counselling on EBF and the presence of family and/or community support have demonstrated improvements in EBF.

Conclusions: Improving the counselling skills of health workers to address breastfeeding problems and increasing community support for breast-feeding are critical components of infant and young child feeding programming, which will aid in attaining the 2025 World Health Assembly EBF targets. Legislation and regulations on marketing of breast-milk substitutes, paid maternity leave and breast-feeding breaks for working mothers require attention in low- and middle-income countries.
\end{abstract}

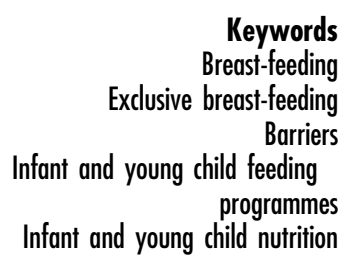

Despite numerous global initiatives on breast-feeding, trend data show exclusive breast-feeding (EBF) rates have stagnated over the last two decades ${ }^{(1,2)}$. In low- and middle-income countries, only $37 \%$ of children younger than 6 months of age are exclusively breast-fed, defined as the proportion of infants aged $0-5$ months who are fed only with breast milk and no additional liquids or solids until 6 months of life ${ }^{(1)}$. Optimal breast-feeding practices have long been known to reduce neonatal and child mortality. Morbidities such as respiratory infections, diarrhoea and otitis media are also decreased, and growing evidence indicates breast-feeding may be protective against obesity and diabetes ${ }^{(1,3)}$. Breast-feeding has maternal benefits, contributing to birth spacing, and longer durations are associated with reductions in ovarian and breast cancer ${ }^{(1)}$. Although some countries have made gains in $\mathrm{EBF}$, early initiation and $\mathrm{EBF}$ rates in many countries are drastically below global targets ${ }^{(4-6)}$. 
Key challenges to EBF remain unaddressed through infant and young child feeding (IYCF) programming. A recent UNICEF report notes that $43 \%$ of newborn babies are fed prelacteal foods or liquids (feeds given to a newborn before breast-feeding is established), which can delay early initiation of breast-feeding, reduce a child's demand for breast milk and lead to difficulties in establishing breast-feeding ${ }^{(6)}$. In addition, most infants are introduced to other foods or liquids too early, prior to the recommended 6 months of age ${ }^{(6-8)}$. The objectives of the present systematic review were (i) to ascertain barriers to EBF in twenty-five low- and middle-income countries according to three domains: maternal issues (prenatal barriers); barriers encountered on the first day, including initiating and establishing EBF; and barriers encountered in maintaining EBF over the first 6 months of life; and (ii) to summarize the programme implications of these findings ${ }^{(9)}$.

\section{Methods}

The purpose of the present systematic review was to determine barriers to EBF in twenty-five US Agency for International Development (USAID) ending preventable child and maternal deaths (EPCMD) priority countries.* The review was conducted following the Preferred Reporting Items for Systematic Review and Meta Analyses (PRISMA) guidelines (see Fig. 1 for the PRISMA flow diagram showing selection of studies).

\section{Inclusion criteria}

To be included in the present review, studies were required to report: (i) data collected on or after 1 January 2000; (ii) human data; (iii) infants as generally healthy; (iv) primary data collection by a researcher, which was inclusive of dissertations and grey literature (non-published documents, such as government, academic or organizational materials); (v) data and findings in Spanish, English or French; and (vi) data from any of the twenty-five USAID EPCMD priority countries.

\section{Exclusion criteria}

Studies were excluded if: (i) infants were reported as ill, premature and/or unhealthy; (ii) reported outcomes did not include EBF; (iii) data included intent to breast-feed without data on EBF practices; (iv) only demographic characteristics of the mother (age, socio-economic status, religion and geographic location) and no other information on EBF were reported; or (v) they were systematic or other reviews.

\footnotetext{
* Afghanistan, Bangladesh, Democratic Republic of Congo, Ethiopia Ghana, Haiti, India, Indonesia, Kenya, Liberia, Madagascar, Malawi, Mali, Mozambique, Myanmar, Nepal, Nigeria, Pakistan, Rwanda, Senegal, South Sudan, Tanzania, Uganda, Yemen and Zambia.
}

Table 1 Literature search strategy for the present systematic literature review on barriers to exclusive breast-feeding in low- and middle-income countries

1. (Breastfeeding OR Breast Feeding OR (Exclusive AND Breastfeeding (All Fields)) OR Lactation OR Infant Nutrition OR Infant Feeding

2. (Problems OR Barriers OR Difficulties OR Determinants) OR Early Discontinuation OR Early Cessation OR Early Termination (Facilitat* OR Promot* OR Support OR Motivat*) OR Duration OR Optimal OR Maintenance OR Guideline Adherence)

3. (Developing Countr* OR low income countr* (All Fields) OR Middle Income Countr* (All Fields) OR LMIC) OR Afghanistan OR Bangladesh OR Democratic Republic of Congo OR DRC OR Ethiopia OR Ghana Or Haiti OR India OR Indonesia OR Kenya OR Liberia OR Madagascar OR Malawi OR Mali OR Mozambique OR Nepal OR Nigeria OR Pakistan OR Rwanda OR Senegal OR South Sudan OR Tanzania OR Uganda OR Yemen OR Priority Country)

4. (English OR Spanish OR French)

5. (Article OR Dissertation)

6. $(>1999)$

7. (\#1 OR \#2 OR \#3 OR \#4 OR \#5) AND \#6

\section{Search strategy and data extraction process}

Four electronic databases, Scopus, MEDLINE, CINAHL and PsychINFO, were searched in September and October 2015 to find eligible studies (see Table 1 for a list of search terms). All search results were first screened by title, and then by abstract, for relevance. The remaining 398 full texts were retrieved for all remaining citations. The texts were evaluated using the Critical Appraisal Skills Programme (CASP) quality criteria by E.L., H.D. and J.A.K. ${ }^{(10)}$, which assessed the methodological quality of relevant studies, including study bias. Raters independently assessed the quality of each study, individual ratings were compared and consensus reached on each criterion. Any disagreements in ratings were discussed until the reviewers reached consensus.

Structured forms were developed to extract information from each article, including study design, outcomes and results (quantitative and qualitative). Data were grouped by subject matter. For the quantitative data extraction, following grouping, data were mined by level of analysis (univariate, bivariate and multivariate), with the highest level of analysis reported and assessed. Data extraction was carried out by E.L., H.D. and J.A.K.

\section{Results}

Following application of the systematic review criteria, from the 4798 records originally identified, forty-eight articles were included in the final review (see Fig. 1). Sixteen barriers to EBF were identified (see Tables 2-4) and grouped according to three categories: (i) prenatal barriers; (ii) barriers at childbirth and during the first day of life; and (iii) barriers in the first 6 months of life. The most frequently reported barrier was 'maternal employment' ( $n$ 23) and the least reported was 'planned length of EBF' $(n 2)$. 


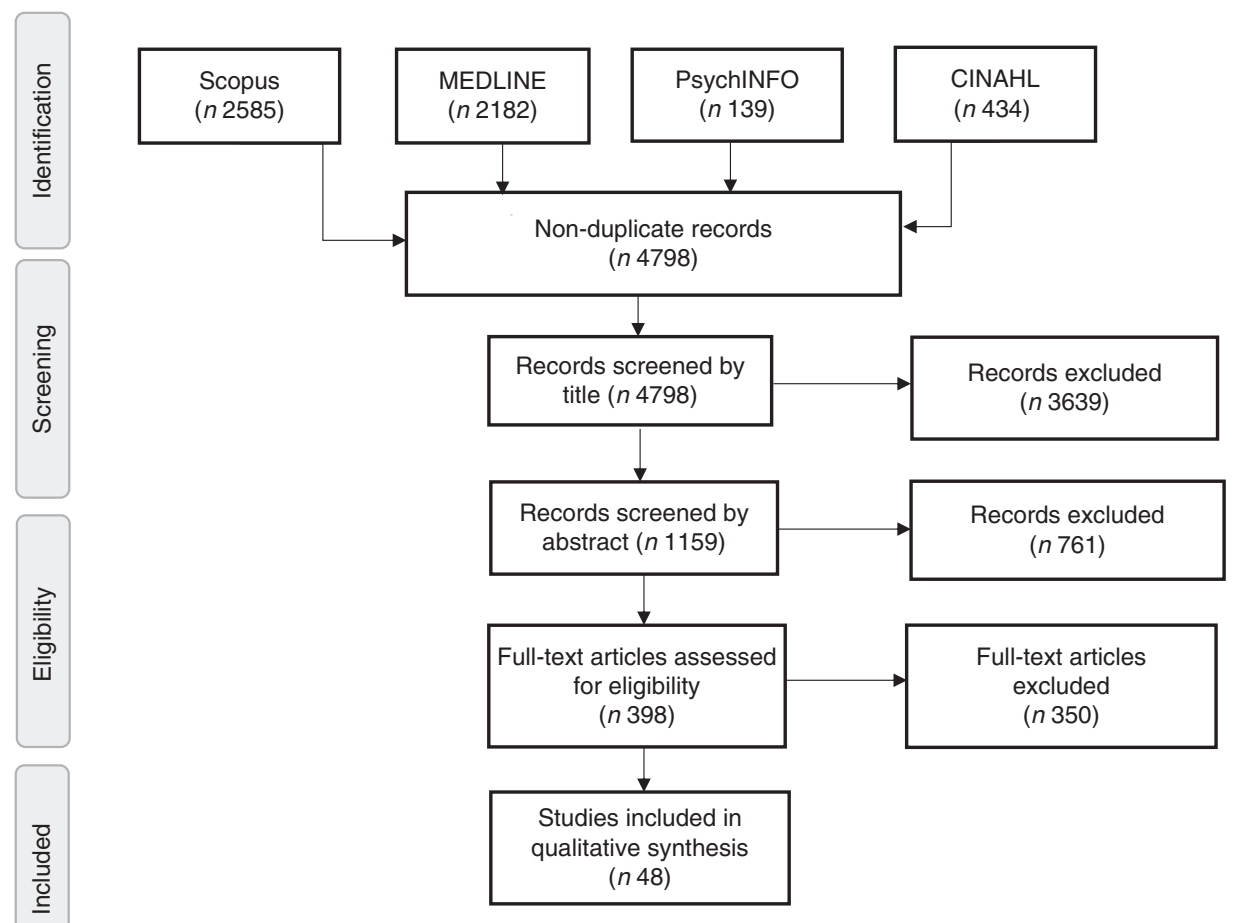

Fig. 1 PRISMA (Preferred Reporting Items for Systematic Review and Meta Analyses) flow diagram: schematic representation of the selection of studies for the present systematic literature review on barriers to exclusive breast-feeding in low- and middle-income countries

Of the twenty-five USAID EPCMD priority countries, fourteen - including Bangladesh, Democratic Republic of Congo, Ethiopia, Ghana, India, Indonesia, Kenya, Malawi, Nepal, Nigeria, Pakistan, Senegal, Tanzania and Uganda - were represented in the current systematic review. About one-third of the studies were reported from Nigeria ( $n$ 11) and India ( $n$ 10). Qualitative data illustrating various barriers are shown in Table 5 .

\section{Prenatal-related barriers to exclusive breast-feeding}

Lack of or late attendance at antenatal care

Antenatal care (ANC) offers an opportunity to counsel women on EBF, among other health topics, in preparation for childbirth and the postpartum period. Fifteen studies described the relationship between ANC attendance and maternal report of EBF. Measurement of ANC attendance varied across studies and included: attendance at any ANC visit, frequency of ANC visits and attendance for a designated number of visits (i.e. $<3$ or $\geq 4$ visits). Ten studies were cross-sectional ${ }^{(11-20)}$, three were mixed-methods ${ }^{(21-23)}$ and two were prospective cohort studies ${ }^{(24,25)}$. Five crosssectional studies reported a significant positive association between ANC attendance and $\mathrm{EBF}^{(14-16,18,20)}$. Women with attendance at any ANC visit were twice as likely to practise EBF compared with women who did not attend ANC (36.4 v. $18 \cdot 2 \%$, respectively; $P=0 \cdot 00, \chi^{2}$ test ${ }^{(16)}$. Women attending four or more ANC visits in Uganda had 3.86 greater odds $(95 \% \mathrm{CI} 1.82,8.31)$ of practising $\mathrm{EBF}$ than women who attended fewer than four ANC visits ${ }^{(14)}$. Similarly, in Ethiopia, women who attended two or three ANC visits were twice as likely ( $95 \%$ CI 1.18, 3.45) to practise EBF than those who only visited once ${ }^{(20)}$.

\section{Poor maternal knowledge of exclusive breast-feeding}

Twelve studies examined the relationship between maternal knowledge of EBF and EBF practices, including seven cross-sectional $^{(12,16,19,20,22,26,27)}$, two mixed-methods ${ }^{(23,28)}$, one cohort $^{(24)}$, one longitudinal ${ }^{(29)}$ and one qualitative study $^{(30)}$. Definitions of maternal knowledge of EBF varied across studies and included: maternal report of EBF definition and related benefits, recommendations and/or best practices. Only three studies found a significant association between maternal knowledge and EBF practices ${ }^{(12,23,24)}$

In Ethiopia, a large cross-sectional study found that mothers with low knowledge of breast-feeding 'best practices' had 3.4 times higher odds of non-EBF than mothers with high knowledge of breast-feeding best practices $^{(12)}$. A mixed-methods study in Tanzania ( $n$ 316) found that those with 'good' breast-feeding knowledge had 2.15 times higher odds of EBF compared with those with poor knowledge ${ }^{(23)}$. In Democratic Republic of Congo, a prospective study revealed that mothers who had a low level of knowledge about breast-feeding had significantly lower odds of EBF at 6 months ${ }^{(24)}$. 
Table 2 Matrix of reviewed papers addressing maternal barriers to exclusive breast-feeding (EBF) in low- and middle-income countries

ANC, antenatal care; DRC, Democratic Republic of Congo.

Maternal barriers to EBF

\begin{tabular}{|c|c|c|c|c|c|c|c|c|c|}
\hline Author & Sample size & Country & Study type & $\begin{array}{c}\text { Attendance at } \\
\text { ANC }\end{array}$ & $\begin{array}{l}\text { Maternal EBF } \\
\text { knowledge }\end{array}$ & $\begin{array}{c}\text { Maternal } \\
\text { employment }\end{array}$ & $\begin{array}{c}\text { Inadequate } \\
\text { maternal nutrition }\end{array}$ & $\begin{array}{c}\text { Maternal } \\
\text { health \& attitudes }\end{array}$ & $\begin{array}{l}\text { Intention } \\
\text { to EBF }\end{array}$ \\
\hline 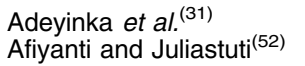 & $\begin{array}{r}300 \\
18\end{array}$ & $\begin{array}{l}\text { Nigeria and Ghana } \\
\text { Indonesia }\end{array}$ & $\begin{array}{l}\text { Cross-sectional } \\
\text { Qualitative }\end{array}$ & & & $x$ & & $x$ & \\
\hline $\begin{array}{l}\text { Aluko-Arowolo and } \\
\text { Adekoya }^{(30)}\end{array}$ & 110 & Nigeria & Qualitative & & $x$ & $x$ & & & \\
\hline Arusei et al ${ }^{(29)}$ & 151 & Kenya & Longitudinal & & $x$ & & & & \\
\hline Aubel et al. ${ }^{(57)}$ & 260 & Senegal & Mixed methods & & & & & & \\
\hline Babakazo et al. ${ }^{(24)}$ & 422 & DRC & Cohort & $\mathrm{x}$ & $\mathrm{x}$ & $\mathrm{x}$ & & $\mathrm{x}$ & $\mathrm{x}$ \\
\hline Chandrashekhar et al. ${ }^{(11)}$ & 385 & Nepal & Cross-sectional & $\hat{x}$ & & & & & \\
\hline Cherop et al. ${ }^{(46)}$ & 384 & Kenya & Cross-sectional & & & $\mathrm{x}$ & & & \\
\hline Diagne-Guéye et al. (26) & 44 & Senegal & Cross-sectional & & $\mathrm{x}$ & $\hat{x}$ & & & \\
\hline Egata et al. ${ }^{(12)}$ & 860 & Ethiopia & Cross-sectional & $x$ & $\mathrm{x}$ & & $\mathrm{x}$ & & \\
\hline Engebretsen et al. ${ }^{(45)}$ & 81 & Uganda & Qualitative & & & $\mathrm{x}$ & $\mathrm{x}$ & & \\
\hline Gewa et al. & 346 & Kenya & Cross-sectional & & & & & & \\
\hline Haider et al (28) & 356 & Bangladesh & Mixed methods & & $\mathrm{x}$ & & & & \\
\hline Joshi et al. ${ }^{(17)}$ & 121 & Bangladesh & Cross-sectional & $\mathrm{x}$ & & $\mathrm{x}$ & & & \\
\hline Kamudoni et al. ${ }^{(36)}$ & 349 & Malawi & Cross-sectional & & & $\hat{x}$ & $\mathrm{x}$ & & \\
\hline Karkee et al. & 639 & Nepal & Cohort & & & & & & \\
\hline Khanal et al. ${ }^{(42)}$ & 649 & Nepal & Cohort & $\mathrm{x}$ & & $x$ & & & \\
\hline Kimani-Murage et al. & 4299 & Kenya & Cohort & & & & & & \\
\hline Kimani-Murage et al. ${ }^{(50)}$ & 110 & Kenya & Qualitative & & & $\mathrm{x}$ & $\mathrm{x}$ & & \\
\hline Kishore et al. ${ }^{(39)}$ & 77 & India & Cross-sectional & & & & & & \\
\hline Mahmood et al.(13) & 123 & India & Cross-sectional & $x$ & & & & $x$ & \\
\hline Maman et al. ${ }^{(55)}$ & 40 & $\mathrm{DRC}$ & Qualitative & & & & & & \\
\hline Maonga et al.(23) & 316 & Tanzania & Mixed methods & $\mathrm{x}$ & $\mathrm{x}$ & $\mathrm{x}$ & & & \\
\hline Matovu et al. ${ }^{(14)}$ & 360 & Kenya & Cross-sectional & $\mathrm{x}$ & & & & & \\
\hline Meshram et al. ${ }^{(44)}$ & 805 & India & Cross-sectional & & & & & & \\
\hline Obilade $^{(47)}$ & 400 & Nigeria & Cross-sectional & & & $x$ & & & \\
\hline Ogunlesi $^{(18)}$ & 262 & Nigeria & Cross-sectional & $\mathrm{x}$ & & $\mathrm{x}$ & & & \\
\hline Okanda et al. ${ }^{(35)}$ & 522 & Kenya & Cross-sectional & & & $\hat{x}$ & & & \\
\hline Olayemi et al. ${ }^{(48)}$ & 744 & Nigeria & Cross-sectional & & & $\hat{x}$ & & & \\
\hline Onah et al. ${ }^{(19)}$ & 400 & Nigeria & Cross-sectional & $\mathrm{x}$ & $\mathrm{x}$ & $\mathrm{x}$ & & & \\
\hline Østergaard and Bula ${ }^{(54)}$ & 21 & Malawi & Qualitative & & & & & & \\
\hline Otoo et al. ${ }^{(33)}$ & 35 & Ghana & Qualitative & & & $\mathrm{x}$ & & $\mathrm{x}$ & \\
\hline Raghavan et al. ${ }^{(43)}$ & 400 & India & Cohort & & & & & & \\
\hline Safari et al. (49) $^{(49)}$ & 130 & Tanzania & Cross-sectional & & & $\mathrm{x}$ & & & \\
\hline Seid et al. ${ }^{(34)}$ & 819 & Ethiopia & Cross-sectional & & & $\mathrm{x}$ & & & $\mathrm{x}$ \\
\hline Setegn et al. ${ }^{(21)}$ & 603 & Ethiopia & Mixed methods & $x$ & & $\hat{x}$ & & & \\
\hline Sharma and Kanani $i^{(37)}$ & 648 & India & Cross-sectional & & & $\hat{x}$ & & & \\
\hline Sohag and Memon ${ }^{(32)}$ & 200 & Pakistan & Cross-sectional & & & $\hat{x}$ & & $x$ & \\
\hline Ssenyonga et al. ${ }^{(38)}$ & 353 & Uganda & Cross-sectional & & & $\mathrm{x}$ & & & \\
\hline Suresh et al. ${ }^{(53)}$ & 400 & India & Cohort & & & & & & \\
\hline Susiloretni et al. (20) & 541 & Indonesia & Cross-sectional & $x$ & $\mathrm{x}$ & & & & \\
\hline Tamiru et al. (22) & 382 & Ethiopia & Cross-sectional & $\hat{x}$ & $\hat{x}$ & & & & \\
\hline Tiwari et al. ${ }^{15)}$ & 279 & India & Cross-sectional & $\hat{x}$ & & & & & \\
\hline Ugboaja et al.(16) & 400 & Nigeria & Cross-sectional & $x$ & $\mathrm{x}$ & & & $\mathrm{x}$ & \\
\hline Ukegbu et al. ${ }^{(40)}$ & 228 & Nigeria & Cohort & & & & & & \\
\hline Webb-Girard et al ${ }^{(56)}$ & 150 & Kenya & Cross-sectional & & & & $x$ & & \\
\hline Yotebieng et al. ${ }^{(27)}$ & 66 & DRC & Cross-sectional & & $x$ & & & & \\
\hline TOTAL & & & & 15 & 12 & 23 & 5 & 6 & 2 \\
\hline
\end{tabular}




\begin{tabular}{|c|c|c|c|c|c|c|c|c|}
\hline \multirow[b]{2}{*}{ Author } & \multirow[b]{2}{*}{ Sample size } & \multirow[b]{2}{*}{ Country } & \multirow[b]{2}{*}{ Study type } & \multicolumn{5}{|c|}{ Barriers to EBF: first day of life } \\
\hline & & & & Place of birth & Type of delivery & $\begin{array}{l}\text { Timing of initiation of } \\
\text { breast-feeding }\end{array}$ & $\begin{array}{l}\text { Prelacteal } \\
\text { feeding }\end{array}$ & $\begin{array}{l}\text { Colostrum feeding } \\
\text { practices }\end{array}$ \\
\hline $\begin{array}{l}\text { Adeyinka et al. } .^{(31)} \\
\text { Afiyanti and Juliastuti }{ }^{(52)}\end{array}$ & $\begin{array}{r}300 \\
18\end{array}$ & $\begin{array}{l}\text { Nigeria and Ghana } \\
\text { Indonesia }\end{array}$ & $\begin{array}{l}\text { Cross-sectional } \\
\text { Qualitative }\end{array}$ & & & & & \\
\hline $\begin{array}{l}\text { Aluko-Arowolo and } \\
\text { Adekoya }^{(30)}\end{array}$ & 110 & Nigeria & Qualitative & & & & & \\
\hline Arusei et al $l_{i}^{(29)}$ & 151 & Kenya & Longitudinal & & & $\mathrm{x}$ & & \\
\hline Aubel et al. ${ }^{(57)}$ & 260 & Senegal & Mixed methods & & & & & \\
\hline Babakazo et al. ${ }^{(24)}$ & 422 & DRC & Cohort & & & & & \\
\hline Chandrashekhar et al. ${ }^{(11)}$ & 385 & Nepal & Cross-sectional & $\mathrm{x}$ & $\mathrm{x}$ & & & $x$ \\
\hline Cherop et al. ${ }^{(46)}$ & 384 & Kenya & Cross-sectional & & & & & \\
\hline Diagne-Guéye et al. ${ }^{(26)}$ & 44 & Senegal & Cross-sectional & & & & & \\
\hline Egata et al. ${ }^{(12)}$ & 860 & Ethiopia & Cross-sectional & & & & $\mathrm{x}$ & $\mathrm{x}$ \\
\hline Engebretsen et al. ${ }^{(45)}$ & 81 & Uganda & Qualitative & & & & $x$ & \\
\hline Gewa et al. & 346 & Kenya & Cross-sectional & & & & & \\
\hline Haider et al.(28) & 356 & Bangladesh & Mixed methods & & & & & \\
\hline Joshi et al. ${ }^{(17)}$ & 121 & Bangladesh & Cross-sectional & $\mathrm{x}$ & $\mathrm{x}$ & & $x$ & $\mathrm{x}$ \\
\hline Kamudoni et al. ${ }^{(36)}$ & 349 & Malawi & Cross-sectional & $x$ & & & & \\
\hline Karkee et al. ${ }^{(42)}$ & 639 & Nepal & Cohort & & $\mathrm{x}$ & & & \\
\hline Khanal et al. ${ }^{(25)}$ & 649 & Nepal & Cohort & & $\hat{x}$ & $x$ & & \\
\hline Kimani-Murage et al. ${ }^{(41)}$ & 4299 & Kenya & Cohort & $\mathrm{x}$ & & & & \\
\hline Kimani-Murage et al. ${ }^{(50)}$ & 110 & Kenya & Qualitative & & & & & \\
\hline Kishore et al. ${ }^{(39)}$ & 77 & India & Cross-sectional & $\mathrm{x}$ & & & & \\
\hline Mahmood et al. ${ }^{(13)}$ & 123 & India & Cross-sectional & $x$ & & & & \\
\hline Maman et al. ${ }^{(55)}$ & 40 & DRC & Qualitative & & & & & \\
\hline Maonga et al. & 316 & Tanzania & Mixed methods & $\mathrm{x}$ & $\mathrm{x}$ & $\mathrm{x}$ & & \\
\hline Matovu et al. ${ }^{(14)}$ & 360 & Kenya & Cross-sectional & $x$ & $x$ & $\hat{x}$ & & \\
\hline Meshram et al. ${ }^{(44)}$ & 805 & India & Cross-sectional & & & $\hat{x}$ & $x$ & $x$ \\
\hline Obilade $^{(47)}$ & 400 & Nigeria & Cross-sectional & & & & & \\
\hline Ogunlesi ${ }^{(18)}$ & 262 & Nigeria & Cross-sectional & $x$ & & & & \\
\hline Okanda et al. ${ }^{(35)}$ & 522 & Kenya & Cross-sectional & $\hat{x}$ & $\mathrm{x}$ & & & \\
\hline Olayemi et al. ${ }^{(38)}$ & 744 & Nigeria & Cross-sectional & & & & & \\
\hline Onah et al. ${ }^{(19)}$ & 400 & Nigeria & Cross-sectional & & $\mathrm{x}$ & & $x$ & $x$ \\
\hline Østergard and Bula ${ }^{(54)}$ & 21 & Malawi & Qualitative & & & & & \\
\hline Otoo et al. ${ }^{(33)}$ & 35 & Ghana & Qualitative & & & & & \\
\hline Raghavan et al. ${ }^{(43)}$ & 400 & India & Cohort & & $\mathrm{x}$ & $x$ & & \\
\hline Safari et al!(49) & 130 & Tanzania & Cross-sectional & & & & & \\
\hline Seid et al. ${ }^{(34)}$ & 819 & Ethiopia & Cross-sectional & $\mathrm{x}$ & $\mathrm{x}$ & & & \\
\hline Setegn et al. ${ }^{(21)}$ & 603 & Ethiopia & Mixed methods & & $\ddot{x}$ & & & \\
\hline Sharma and Kanani & 648 & India & Cross-sectional & $\mathrm{x}$ & $x$ & & & \\
\hline Sohag and Memon ${ }^{(32)}$ & 200 & Pakistan & Cross-sectional & & & & & \\
\hline Ssenyonga et al. ${ }^{(38)}$ & 353 & Uganda & Cross-sectional & $x$ & $x$ & & & \\
\hline $\begin{array}{l}\text { Suresh et al. } \\
\text { Susiloretni et al (20) }\end{array}$ & 400 & India & Cohort & & & & & \\
\hline Susiloretni et al. ${ }^{(20)}$ & 541 & Indonesia & Cross-sectional & $x$ & & $\mathrm{x}$ & $x$ & $x$ \\
\hline Tamiru et al & 382 & Ethiopia & Cross-sectional & & & & & $x$ \\
\hline Tiwari et al. ${ }^{(15)}$ & 279 & India & Cross-sectional & $x$ & $\mathrm{x}$ & $\mathrm{x}$ & & $\mathrm{x}$ \\
\hline Ugboaja et al.(16) & 400 & Nigeria & Cross-sectional & & & & & \\
\hline Ukegbu et al. ${ }^{(40)}$ & 228 & Nigeria & Cohort & $x$ & $\mathrm{x}$ & & $\mathrm{x}$ & $x$ \\
\hline Webb-Girard et al. ${ }^{(56)}$ & 150 & Kenya & Cross-sectional & & & & & \\
\hline Yotebieng et al. . $^{(27)}$ & 66 & DRC & Cross-sectional & & & & & \\
\hline TOTAL & & & & 16 & 15 & 8 & 7 & 9 \\
\hline
\end{tabular}


Table 4 Matrix of reviewed papers addressing continued barriers to exclusive breast-feeding (EBF) in the first 6 months of life in low- and middle-income countries

Continued barriers to EBF in the first 6 months of life

\begin{tabular}{|c|c|c|c|c|c|c|c|c|}
\hline Author & Sample size & Country & Study type & $\begin{array}{l}\text { Perceived infant } \\
\text { health \& cues }\end{array}$ & $\begin{array}{l}\text { Perceptions of } \\
\text { insufficient milk }\end{array}$ & $\begin{array}{l}\text { Breast-feeding } \\
\text { problems }\end{array}$ & $\begin{array}{l}\text { Counselling on } \\
\text { breast-feeding }\end{array}$ & $\begin{array}{l}\text { Family and community } \\
\text { support for EBF }\end{array}$ \\
\hline Adeyinka et al. ${ }^{(31)}$ & 300 & Nigeria and Ghana & Cross-sectional & $x$ & & & $\mathrm{x}$ & $x$ \\
\hline Afiyanti and Juliastuti( ${ }^{(52)}$ & 18 & Indonesia & Qualitative & $\mathrm{x}$ & $\mathrm{x}$ & & & $\mathrm{x}$ \\
\hline $\begin{array}{l}\text { Aluko-Arowolo and } \\
\text { Adekoya }^{(30)}\end{array}$ & 110 & Nigeria & Qualitative & & & & & $\mathrm{x}$ \\
\hline Arusei et al. (29) & 151 & Kenya & Longitudinal & & & & & \\
\hline Aubel et al. ${ }^{(57)}$ & 260 & Senegal & Mixed methods & & & & & $\mathrm{x}$ \\
\hline Babakazo et al. ${ }^{(24)}$ & 422 & DRC & Cohort & & & $\mathrm{x}$ & & \\
\hline Chandrashekhar et al. ${ }^{(11)}$ & 385 & Nepal & Cross-sectional & & & $\mathrm{x}$ & & $\mathrm{x}$ \\
\hline Cherop et al. ${ }^{(46)}$ & 384 & Kenya & Cross-sectional & $x$ & $\mathrm{x}$ & & & \\
\hline Diagne-Guéye et al. ${ }^{(26)}$ & 44 & Senegal & Cross-sectional & & & & & \\
\hline Egata et al. ${ }^{(12)}$ & 860 & Ethiopia & Cross-sectional & & & & & \\
\hline Engebretsen et al. ${ }^{(45)}$ & 81 & Uganda & Qualitative & $\mathrm{x}$ & & & & $\mathrm{x}$ \\
\hline Gewa et al. & 346 & Kenya & Cross-sectional & $\hat{x}$ & & & & \\
\hline Haider et al. (28) & 356 & Bangladesh & Mixed methods & $\hat{x}$ & & & & $x$ \\
\hline Joshi et al. ${ }^{(17)}$ & 121 & Bangladesh & Cross-sectional & & & & $\mathrm{x}$ & \\
\hline Kamudoni et al. ${ }^{(36)}$ & 349 & Malawi & Cross-sectional & & & & 人 & \\
\hline Karkee et al..$^{(42)}$ & 639 & Nepal & Cohort & & & $\mathrm{x}$ & & \\
\hline Khanal et al. ${ }^{(25)}$ & 649 & Nepal & Cohort & & & & $\mathrm{x}$ & $x$ \\
\hline Kimani-Murage et al. ${ }^{(41)}$ & 4299 & Kenya & Cohort & & & & 凡 & 人 \\
\hline Kimani-Murage et al. ${ }^{(50)}$ & 110 & Kenya & Qualitative & $\mathrm{x}$ & & & $\mathrm{x}$ & \\
\hline Kishore et al. & 77 & India & Cross-sectional & & & & $\hat{x}$ & \\
\hline Mahmood et al. ${ }^{(13)}$ & 123 & India & Cross-sectional & $x$ & $x$ & & $x$ & \\
\hline Maman et al. ${ }^{(55)}$ & 40 & DRC & Qualitative & & $\mathrm{x}$ & & & \\
\hline Maonga et al.(23) & 316 & Tanzania & Mixed methods & & & & $\mathrm{x}$ & \\
\hline Matovu et al. ${ }^{(14)}$ & 360 & $\begin{array}{l}\text { Kenya } \\
\text { Kent }\end{array}$ & Cross-sectional & & $\mathrm{x}$ & & $\mathrm{x}$ & $x$ \\
\hline Meshram et al. ${ }^{(44)}$ & 805 & India & Cross-sectional & & & & & \\
\hline Obilade $^{(47)}$ & 400 & Nigeria & Cross-sectional & & & & & \\
\hline Ogunlesi ${ }^{(18)}$ & 262 & Nigeria & Cross-sectional & & & & & \\
\hline Okanda et al. ${ }^{(35)}$ & 522 & Kenya & Cross-sectional & & & & & \\
\hline Olayemi et al. (48) $^{-1}$ & 744 & Nigeria & Cross-sectional & & & & & $x$ \\
\hline Onah et al. ${ }^{(19)}$ & 400 & Nigeria & Cross-sectional & & & & & \\
\hline Østergaard and Bula ${ }^{(54)}$ & 21 & Malawi & Qualitative & & $\mathrm{x}$ & & $\mathrm{x}$ & $\mathrm{x}$ \\
\hline Otoo et al. & 35 & Ghana & Qualitative & $\mathrm{x}$ & & $\mathrm{x}$ & & $\hat{x}$ \\
\hline Raghavan et al. ${ }^{(43)}$ & 400 & India & Cohort & & & & $x$ & \\
\hline Safari et al. ${ }^{(49)}$ & 130 & Tanzania & Cross-sectional & & & $\mathrm{x}$ & & \\
\hline Seid et al. ${ }^{(34)}$ & 819 & Ethiopia & Cross-sectional & & & & $\mathrm{x}$ & \\
\hline Setegn et al. ${ }^{(21)}$ & 603 & Ethiopia & Mixed methods & & & & & \\
\hline Sharma and Kanani ${ }^{(37)}$ & 648 & India & Cross-sectional & & & & $\mathrm{x}$ & \\
\hline Sohag and Memon (32) & 200 & Pakistan & Cross-sectional & $\mathrm{x}$ & $\mathrm{x}$ & $\mathrm{x}$ & & \\
\hline Ssenyonga et al (38) & 353 & Uganda & Cross-sectional & & & & $x$ & \\
\hline Susiloretni et al. (20) & 541 & Indonesia & Cross-sectional & & & & & \\
\hline Suresh et al. ${ }^{(53)}$ & 400 & India & Cohort & $\mathrm{x}$ & $\mathrm{x}$ & $\mathrm{x}$ & & $\mathrm{x}$ \\
\hline Tamiru et al (22) & 382 & Ethiopia & Cross-sectional & & & & & \\
\hline Tiwari et al. ${ }^{(15)}$ & 279 & India & Cross-sectional & & & & & \\
\hline Ugboaja et al.(16) & 400 & Nigeria & Cross-sectional & & & & $x$ & $\mathrm{x}$ \\
\hline Ukegbu et al. ${ }^{(40)}$ & 228 & Nigeria & Cohort & & & & & $x$ \\
\hline Webb-Girard et al. (56) $^{(56)}$ & 150 & Kenya & Cross-sectional & & & & & \\
\hline Yotebieng et al. ${ }^{(27)}$ & 66 & DRC & Cross-sectional & & $\mathrm{x}$ & & & $x$ \\
\hline TOTAL & & & & 11 & 9 & 7 & 14 & 17 \\
\hline
\end{tabular}

DRC, Democratic Republic of Congo. 
Table 5 Selected quotes from qualitative studies addressing barriers to exclusive breast-feeding (EBF) in low-and middle-income countries

\begin{tabular}{|c|c|c|}
\hline Barrier to breast-feeding & Country & Illustrative quote on theme \\
\hline Maternal EBF knowledge & Tanzania & $\begin{array}{l}\text { 'You see when this baby was } 2 \text { months even after breast-feeding he continued crying, } \\
\text { but when I started giving him cassava porridge he became calm. My milk was not } \\
\text { enough to satisfy his hunger and this is usual at this age.(23) (Woman of reproductive } \\
\text { age, aged } 23 \text { years) }\end{array}$ \\
\hline \multirow[t]{3}{*}{ Maternal employment } & Nigeria & $\begin{array}{l}\text { 'Although it's being said in the hospital that } 6 \text { months is very good [for EBF], but in a } \\
\text { situation whereby the maternity leave is just } 3 \text { months ... because of exclusive } \\
\text { breast-feeding [one can] lose her job ...'(30) }\end{array}$ \\
\hline & Urban Kenya & $\begin{array}{l}\text { 'At times, it's the challenge of work; you are supposed to breast-feed, yet you are } \\
\text { supposed to go to work. The mother gets problems, and the way life is hard } \\
\text { nowadays, you are forced to go fend for yourself whether you have a baby or not. } \\
\text { So you have to leave the baby.' (50) }\end{array}$ \\
\hline & Rural Uganda & 'Some working mothers have no option but to introduce other feeds.'(45) \\
\hline \multirow[t]{3}{*}{ Inadequate maternal nutrition } & Uganda & $\begin{array}{l}\text { 'Poverty makes me fail to buy food and so I don't eat a balanced diet which limits the } \\
\text { milk for the baby.'(45) }\end{array}$ \\
\hline & Kenya & $\begin{array}{l}\text { 'If you eat well, breast milk alone can be adequate but if you do not eat well then it will } \\
\text { not be adequate ... }(50)\end{array}$ \\
\hline & Kenya & $\begin{array}{l}\text { 'I don't eat sufficient amounts of food currently so I don't think it [breast milk only] will } \\
\text { be enough for all these months.'(56) }\end{array}$ \\
\hline $\begin{array}{l}\text { Timing of initiation of } \\
\text { breast-feeding }\end{array}$ & Kenya & $\begin{array}{l}\text { 'For me, the moment I give birth and I am given my baby, I breast-feed the baby so as } \\
\text { to get the yellow milk. It helps the baby's brain development. I'm speaking about my } \\
\text { practice.'(50) (FGD, older mother) }\end{array}$ \\
\hline \multirow[t]{3}{*}{ Prelacteal feeding } & Rural Uganda & $\begin{array}{l}\text { 'My mother stopped me from giving breast milk unless I first gave sugar water.'(45) } \\
\text { (Rural FGD, Naka-loke, woman) }\end{array}$ \\
\hline & Nigeria & $\begin{array}{l}\text { 'While waiting for the breast milk to flow, it is good to give baby water or glucose water, } \\
\text { after all water is the life of a fish.'(40) (26-year-old participant in one of the FGD } \\
\text { sessions) }\end{array}$ \\
\hline & Nigeria & '... it is good to give water so as to sustain the baby before breast milk starts to flow. ${ }^{\prime}(40)$ \\
\hline $\begin{array}{l}\text { Perceived infant health and } \\
\text { cues }\end{array}$ & Kenya & $\begin{array}{l}\text { 'I breast-fed him. I breast-fed him when I got out of the hospital and when I noticed that } \\
\text { he had stomach upsets I introduced him to water.'(50) (IDI, young mother, Viwandani) }\end{array}$ \\
\hline Perceptions of insufficient milk & Indonesia & $\begin{array}{l}\text { 'At exactly } 3 \text { months old, my baby has got fussy. He didn't sleep during the night. I tried } \\
\text { to do anything. I carried him. I had breast-fed him until my breast milk dried out, my } \\
\text { breasts were deflated. So, at the end I thought that my breast milk was not enough } \\
\text { for him, therefore he was continually hungry.'(52) }\end{array}$ \\
\hline Breast-feeding problems & Uganda & $\begin{array}{l}\text { 'Sickness like malaria and breast problems like breast engorgement which are very } \\
\text { common here do not allow the mothers to breast-feed exclusively.' }{ }^{\text {' } 45)} \text { (FGD, man) }\end{array}$ \\
\hline Counselling on breast-feeding & Malawi & $\begin{array}{l}\text { 'That the timing of the counselling was inappropriate as it took place right after they } \\
\text { had received their HIV test result. They felt overwhelmed with confusion, fear, and } \\
\text { other emotions and thus unable to process information on how to breast-feed a ye } \\
\text { unborn child.'(54) }\end{array}$ \\
\hline \multirow[t]{3}{*}{$\begin{array}{l}\text { Family and community support } \\
\text { for EBF }\end{array}$} & Malawi & $\begin{array}{l}\text { 'My mother just decided that the child should start eating porridge but for me I did not } \\
\text { want to do that. I don't know why my mother did that because she just cooked the } \\
\text { porridge and bring it to me and then started feeding my baby. I tried to reason with } \\
\text { her not to do so but she could not listen to me. }{ }^{\text {(54) }}\end{array}$ \\
\hline & Indonesia & $\begin{array}{l}\text { 'Because my baby was crying every night, my mother tried to give him rice flour. It was } \\
\text { diluted with some water like breast milk. My baby stopped crying after that.. } 52 \text { ) }\end{array}$ \\
\hline & Nigeria & $\begin{array}{l}\text { 'At the early stage my husband agreed on EBF, but after } 3 \text { months he said our baby } \\
\text { was losing weight and therefore asked me to add artificial milk to help her.'(40) }\end{array}$ \\
\hline
\end{tabular}

FGD, focus group discussion; IDI, in-depth interview.

\section{Maternal health and attitudes}

Six studies examined the relationship between maternal health and attitudes regarding desire and ability to breastfeed and EBF practices, including four cross-sectional studies $^{(13,16,31,32)}$, one cohort study ${ }^{(24)}$ and one qualitative study ${ }^{(33)}$. Measures of maternal health and attitudes differed across studies and included personal frustrations, confidence in one's ability to breast-feed, stress and maternal illness. A cohort study found that Congolese women who described themselves as 'not confident' in their ability to breast-feed were more likely to cease EBF than those who reported being 'very confident' (adjusted hazard ratio $=3.9$; $P=0.002)^{(24)}$. Congolese women's attitudes towards breastfeeding, whether positive or negative, were not found to affect EBF practices ${ }^{(24)}$. Up to one-third of mothers in
Pakistan, Nigeria and Ghana reported ceasing breast-feeding for their own physical or mental health, indicating that breast-feeding was a stressful, frustrating and/or painful experience, due to illness or breast problems ${ }^{(16,31,32)}$.

\section{Lack of intention to practise exclusive breast-feeding}

Two studies examined the relationship between having a plan to exclusively breast-feed and EBF practices ${ }^{(24,34)}$. A cohort study found that women with a prenatal EBF plan had 3.75 times higher likelihood of practising EBF than those who did not $^{(34)}$. A large cross-sectional study in Democratic Republic of Congo found that women who had no planned length of EBF were 2.9 times more likely to discontinue EBF than those who planned to breast-feed exclusively $^{(24)}$. 
Barriers to exclusive breast-feeding: first day of life

Delivery outside a bealth facility

Sixteen studies examined the relationship between the place of birth and EBF practices. Thirteen studies were cross-sectional $^{(11,13-15,17,18,20,34-39)}$, two were cohort studies $^{(40,41)}$ and one was a mixed-methods study ${ }^{(23)}$. Seven studies found a significant and positive association between delivery in a health facility and EBF practices $^{(11,13,15,17,23,35,39)}$. Two studies in Ethiopia and Uganda found a two to three times higher likelihood of practising $\mathrm{EBF}$ in women who delivered in a health facility than those who delivered at home ${ }^{(34,38)}$. Similarly, a crosssectional study in Nigeria showed that those who delivered outside a health facility were less likely to practise $\mathrm{EBF}(\mathrm{OR}=2 \cdot 6 ; P=0 \cdot 049)^{(18)}$

\section{Delivery by caesarean section v. vaginal birth}

Fifteen studies examined the association between method of delivery and EBF practices: nine crosssectional $^{(11,14,15,17,19,34,35,37,38)}$, four cohort ${ }^{(25,40,42,43)}$ and two mixed-methods studies ${ }^{(21,23)}$. One study was observational and did not perform statistical analysis on the aforementioned association ${ }^{(40)}$. Six of these studies found a significant relationship between type of delivery and EBF practice $(11,14,25,37,38,42)$

Five studies found mothers were 2.28 to 10.54 times more likely to exclusively breast-feed following vaginal birth in comparison to infants delivered through caesarean section $^{(11,14,34,37,38)}$

Two studies examined the relationship between caesarean birth and cessation of $\mathrm{EBF}^{(25,42)}$. A large study in Nigeria found that women who delivered by caesarean section were $29 \%$ less likely to practise EBF than those who delivered vaginally ${ }^{(19)}$. Similarly, in Nepal, study findings revealed that women with a vaginal delivery had 7.6 times greater likelihood of EBF than those who delivered via caesarean section $(P=0.008)^{(11)}$.

Timing of initiation of breast-feeding: early $\mathrm{v}$. delayed Eight studies assessed the relationship between initiation of breast-feeding and the practice of EBF within the first 6 months, including four cross-sectional ${ }^{(14,15,20,44)}$, two prospective cohort studies ${ }^{(25,43)}$, one mixed-methods ${ }^{(23)}$ and one longitudinal study ${ }^{(29)}$. Five studies found a significant positive association between early initiation of breast-feeding, defined as within the first hour following childbirth, and the continued practice of EBF at 6 weeks, 10 weeks and 6 months after birth ${ }^{(14,15,29,43,44)}$.

A study in Uganda reported that women who initiated breast-feeding early were more likely to adhere to EBF than women who delayed initiation for more than an hour following childbirth (adjusted OR $=10 \cdot 17$; 95\% CI 4.52 , $22 \cdot 88)^{(14)}$. In India, findings from a cohort study revealed that women who initiated breast-feeding more than an hour after birth were at a higher risk of ceasing EBF by
6 weeks (relative risk $=1.77 ; 95 \%$ CI 1.1, 2.84) ${ }^{(43)}$. This same study named maternal perception of inadequacy of milk, nipple problems, pain and difficulty in sitting up, and breast refusal as challenges that play a role in the decision to delay initiation of breast-feeding beyond the first hour of life ${ }^{(43)}$.

\section{Prelacteal feeding}

Prelacteal feeding is defined as giving foods and/or liquids, other than colostrum, to an infant prior to establishing breast-feeding. Seven studies examining prelacteal feeding and EBF practices were identified, with five crosssectional studies, one qualitative and one cohort study $^{(12,17,19,20,40,44,45)}$. Observational data revealed that prelacteal feeding prevalence ranges from 13 to $76 \%$, depending on the country context. Glucose water, infant formula, honey, cow's or buffalo's milk, or water were cited as common prelacteal feeds ${ }^{(12,17,19,20,44,45)}$. In Ethiopia, although $76 \%$ of mothers gave prelacteal feeds, prelacteal feeding was not associated with non-EBF, following bivariate analyses ${ }^{(12)}$. In Nigeria, a large crosssectional study showed that when breast milk was given as first feed, women had a 3.4 times higher likelihood of EBF (95\% CI 1.75, 6.66) compared with infant formula as a first feed, which lowered likelihood of EBF by $46 \%{ }^{(19)}$.

Colostrum feeding practices - discarding of the colostrum Nine studies examined whether feeding colostrum, the 'first milk', is associated with EBF. This included seven cross-sectional studies ${ }^{(11,12,15,17,19,20,44)}$, one mixedmethods $^{(22)}$ and one cohort study ${ }^{(40)}$. Two studies found a statistically significant association between providing or discarding colostrum and the likelihood of $\mathrm{EBF}^{(11,22)}$.

In Ethiopia, discarding colostrum was associated with higher odds of non-EBF during the first 6 months (adjusted $\mathrm{OR}=1.78 ; 95 \%$ CI 1.09, 4.94), after taking confounding variables into account ${ }^{(22)}$. In Nepal, a multivariate analysis showed that women who fed colostrum had a $27 \cdot 2$ times greater likelihood of EBF for 6 months compared with those who gave other foods as a first feed $(P<0 \cdot 001)^{(11)}$. Reasons reported for discarding colostrum included receipt of advice from elders, that it was 'not good for health', 'the child could get sick' and that colostrum was 'difficult for child to digest' ${ }^{\text {(44) }}$.

\section{Barriers to maintaining exclusive breast-feeding in the first 6 months of life}

Maternal employment

Full-time employment may limit the ability of women to breast-feed their children, considering women without maternity leave, those who work long hours outside the home, those who perform physical labour or those without workplace protections, such as breaks for breast-feeding. Twenty-three studies examined maternal employment in relation to $\mathrm{EBF}$ practices, including fifteen crosssectional $^{(17-19,26,31,32,34-38,46-49)}$, four qualitative ${ }^{(30,33,45,50)}$, 
two mixed-methods ${ }^{(21,23)}$ and two cohort studies ${ }^{(24,25)}$. Definitions of maternal employment varied across the studies and included employment status, type of occupation, return to work following childbirth and/or employment cited as a barrier to EBF. Seven studies (six cross-sectional and one mixed-methods) reported a statistically significant association between maternal employment and $\mathrm{EBF}^{(18,21,31,34,47-49)}$.

Five of these seven studies found women who selfdefined as a housewife or as unemployed were more likely to practise EBF than woman who had formal employment ${ }^{(18,21,34,48,49)}$. A cross-sectional study from Nigeria found that women who returned to work had a $51.8 \%$ lower likelihood of practising EBF than those who did not $(P<0.05)^{(48)}$. A similar finding was reported in Nigeria among women professionals who did not practise $\operatorname{EBF}(P=0 \cdot 024)^{(18)}$. In Ethiopia and Tanzania, three studies found that women who remained unemployed or were noted as housewives had between 2.2 and 10.4 times higher odds of practising EBF (compared with women in formal employment $)^{(21,34,49)}$.

\section{Perceptions of poor infant behaviour, bealth and cues of feeding problems}

The perceived behaviours of an infant can be cues for a mother in regard to her decision and/or ability to exclusively breast-feed. Eleven studies examined perceived infant behaviours and/or health in relation to EBF practices. These included five cross-sectional ${ }^{(13,31,32,46,51)}$, four qualitative $^{(33,45,50,52)}$, one cohort ${ }^{(53)}$ and one mixedmethods study ${ }^{(28)}$. Infant behaviours and cues included interpretation of crying, fussiness, and perceived receipt of adequate nutrition for the infant and infant health, which included perceptions of health in relation to other infants of a similar age. Only one study performed a full multivariate analysis and found that maternal perception of infant health was not associated with breast-feeding practices $^{(51)}$. Cross-sectional studies reported the following reasons for not exclusively breast-feeding: infant gaining insufficient weight, colic, breast-feeding suckling difficulties and perceptions that infants were not satiated by breast-feeding ${ }^{(53)}$.

\section{Perceptions of insufficient breast milk}

Nine studies examined the relationship of maternal perception of insufficient milk with EBF practices: four cross-sectional $^{(13,14,32,46)}$, three qualitative ${ }^{(52,54,55)}$, one mixed-methods ${ }^{(27)}$ and one cohort study ${ }^{(53)}$. Five studies, inclusive of four cross-sectional and one cohort study, provided observational data on insufficient milk and related insufficient breast milk to EBF practices ${ }^{(13,32,46,53)}$. A study conducted with Ugandan women reported that women who believed they could produce enough breast milk were 3.9 times more likely to practise EBF than women who believed their breast milk was 'not enough $^{\text {(14) }}$. Insufficient milk or inadequate milk secretion was cited as a primary reason for ceasing to exclusively breast-feed and introduce other foods and liquids in two studies in India ${ }^{(13,53)}$. Qualitative data revealed mothers perceived their breast milk to be lacking in quantity to nourish infants and introduced other foods, such as porridge and fruit, as a way to satiate infants and calm cries of hunger or fussiness ${ }^{(52,54,55)}$.

\section{Perceived inadequate maternal nutrition}

Five studies examined maternal diet and EBF: two crosssectional $^{(12,36)}$, two qualitative ${ }^{(45,50)}$ and one mixed-methods that used both quantitative and qualitative data ${ }^{(56)}$. Maternal nutrition was described within the context of household food insecurity and the ability to purchase food or the lack of staple foods (i.e. maize) for a period of time. Neither cross-sectional study found a significant association between maternal nutrition and EBF practices ${ }^{(12,36)}$. Qualitative data described the linkage between mothers 'eating well' and 'sufficient amounts of food' and breast milk sufficiency (see Table 5) ${ }^{(45,50,56)}$.

\section{Breast-feeding problems}

Seven studies examined the relationship between breastfeeding problems and EBF practices, including three crosssectional studies ${ }^{(11,32,49)}$, three cohort studies ${ }^{(24,42,53)}$ and one qualitative study ${ }^{(33)}$. Breast-feeding problems are defined as physical breast problems, which included mastitis, breast engorgement, and cracked or inverted nipples. Of the quantitative studies, three studies reported descriptive information $^{(32,49,53)}$, one reported bivariate analyses ${ }^{(42)}$ and two performed multivariate analysis ${ }^{(11,24)}$. Two cohort studies found a significant negative association between breastfeeding problems and likelihood of $\mathrm{EBF}^{(24,42)}$. In Democratic Republic of Congo, mothers with breast-feeding problems during the first week were 1.5 times more likely to cease EBF during the first 6 months than mothers without breastfeeding problems ${ }^{(24)}$. Similarly, in Nepal, breast-feeding problems were significantly associated with cessation of EBF (adjusted hazard ratio $=2 \cdot 07 ; 95 \%$ CI 1.66, 2.57; $P<0 \cdot 001$ ) at 4,12 or 22 weeks following delivery, and urban mothers were more likely than rural mothers to cease breast-feeding early ${ }^{(42)}$. In Tanzania and Pakistan, $4-12 \%$ of mothers reported breast problems, such as engorgement, breast pain, cracked nipples and mastitis, as a contributing factor to non$\mathrm{EBF}^{(32,49)}$. Focus group discussions with Ghanaian mothers described breast and nipple problems, including swollen and painful breasts, breast abscesses and sore nipples, as important barriers to $\mathrm{EBF}^{(33)}$.

\section{Counselling on breast-feeding}

Fourteen studies examined the association between counselling on breast-feeding and EBF. These included nine cross-sectional studies ${ }^{(13,14,16,17,31,34,37-39)}$, two qualitative studies $^{(50,54)}$, two cohort studies ${ }^{(25,43)}$ and one mixedmethods study ${ }^{(23)}$. Of the twelve quantitative studies, four studies reported a significant and positive association 
between counselling and $\mathrm{EBF}^{(14,25,34,37)}$. Two studies in Ethiopia reported that mothers who were counselled on infant feeding practices had a greater likelihood of exclusively breast-feeding ${ }^{(34,37)}$. A study in Nepal examined the effect of types of breast-feeding advice on cessation of EBF and found that mothers who received the advice 'breastfeeding on demand' and 'not to provide pacifier or teats' were less likely to cease EBF practice before 6 months ${ }^{(25)}$. In Uganda, one study showed that HIV-positive mothers benefited more from individual counselling than group counselling for improving EBF practices ${ }^{(14)}$.

\section{Family and community support for exclusive breast-feeding}

Seventeen studies examined the relationship between family and community support and EBF practices. Six studies were cross-sectional ${ }^{(11,14,16,31,33,48)}$, five were qualitative $^{(30,33,45,52,54)}$, three were cohort ${ }^{(25,40,53)}$ and three were mixed-methods studies ${ }^{(27,28,57)}$. Twelve of seventeen studies reported observational or qualitative data on types of family and community support (defined as presence of grandmothers in the household, grandmother's and father's feeding preferences, advice or preference from friends and/or the community, and/or husband's assistance during breastfeeding) and $\mathrm{EBF}^{(16,25,27,28,30,31,33,45,52-54,57)}$. Seven of eight qualitative studies indicated that grandmothers have an influential role in infant feeding practices $(27,28,33,43,52,54,57)$. Most women described the grandmother (i.e. mother of study participant or mother-in-law) as a key influencer of feeding practices, either providing advice on early introduction of foods or actively feeding the infant during the first 6 months, with or without the mother's consent (see Table 5).

Mothers reported that grandmothers preferred mothers to adopt the same feeding practices as their own generation ${ }^{(33)}$.

Two studies reported a significant and positive association between family and community support and $\mathrm{EBF}^{(11,40)}$. In Nepal, having friends who exclusively breastfed had a positive impact on the EBF practices of women $^{(11)}$. In Nigeria, family attitudes towards EBF were examined $^{(40)}$. Among women, $44 \%$ who cited a family environment of positivity towards EBF practised EBF, while only $29 \%$ of those who perceived a negative family attitude towards EBF practised it $(P=0 \cdot 028)$. In Nigeria, reasons for discontinuing or not practising EBF included it not being culturally acceptable, husband refusal to allow EBF or receipt of advice from elders to discontinue ${ }^{(16)}$. Social support was identified as an aid in continuing EBF in Nigeria and Ghana ${ }^{(31)}$.

\section{Discussion}

Our search of the academic and grey literature found sixteen barriers to EBF in the first 6 months of life in fourteen USAID EPCMD priority countries. These barriers were sub-categorized into prenatal barriers, barriers during the first $24 \mathrm{~h}$ after birth and barriers that extend through the first 6 months. Our analysis is congruent with recent findings on impediments to $\mathrm{EBF}$ practices ${ }^{(58,59)}$. We conclude that there is moderate evidence (i.e. at least five studies) of a negative association between maternal employment and EBF due to mixed results from quantitative and qualitative studies. Data on intent to breast-feed were limited and it is unclear as to its effect on EBF practices.

Studies that investigated barriers at childbirth and the initial $24 \mathrm{~h}$ after delivery found strong evidence that type of delivery, particularly caesarean section, can impede EBF practices. The current review reveals moderate evidence for early initiation of breast-feeding and likelihood of practising EBF. Breast-feeding problems and perceived insufficient breast milk were commonly reported, yet data emanated from weak study designs (i.e. cross-sectional or observational). Our review reveals that counselling on EBF and the presence of family and/or community support have some impact on improved EBF practices, given that half of studies showed associations of significance. It is unclear as to the role of perceived infant behaviours/cues in EBF practices, given limited evidence.

\section{Promising interventions and programmatic implications of the current review}

\section{Workplace support for breast-feeding}

Half of the identified studies in our review demonstrated that support for EBF is challenging for women in formal employment. Our findings are similar those reported from Ethiopia, Kenya and Brazil, which show that women who self-define as 'unemployed' tend to have better EBF practices than their formally employed counterparts ${ }^{(12,60-62)}$. Lack of on-site child care; absence of physical areas to support breast-feeding, such as breast-feeding rooms or breast pumps; and short maternity leave are common obstacles to EBF for working mothers ${ }^{(63-65)}$. Available global guidance for employers provides key actions to support breast-feeding in the workplace, to enforce country policies on paid maternity leave, and to facilitate a supportive working environment for breast-feeding ${ }^{(66-68)}$.

\section{Caesarean delivery and exclusive breast-feeding}

According to findings from the current review, giving birth by caesarean section is a substantial barrier to EBF practices. A recent systematic review reported that rates of early initiation of breast-feeding were lower after caesarean section compared with vaginal birth, and full/exclusive breast-feeding at 6 months was lower following caesarean delivery ${ }^{(69)}$. Practices surrounding caesarean deliveries may create barriers to EBF, including no skin-to-skin contact, separation of mother and infant, and delayed initiation of breast-feeding, which are compounded by longer recovery times and reported late onset of full lactation ${ }^{(70-72)}$. 
Postpartum fatigue, pain and complications associated with caesarean delivery should also be considered regarding breast-feeding behaviours, which can contribute to early cessation of $\mathrm{EBF}^{(73)}$. Mothers and families should receive encouragement and support for rooming-in of mother and infant, support to learn how to manually express breast milk during separation, and discouragement from use of formula for satiating hunger and from early cessation of breastfeeding, unless medically indicated.

\section{Strengthening bealth-worker skills at health facilities and} Baby-Friendly Hospital Initiative

Our findings reveal the need to address difficulties with EBF, such as physical breast problems or perceptions of insufficient milk, so women can EBF for the full 6-month duration. Health workers play a critical role in EBF counselling and should be equipped with the necessary skills to address breast-feeding problems during ANC and postnatal care, especially in light of recent WHO ANC guidelines $^{(74)}$. The development of practical, simple guidance and job aids on how to identify and address breastfeeding difficulties may aid overburdened health providers, who often face high demands on time and provide multiple services.

A recent systematic review of randomized controlled trials of the Baby-Friendly Hospital Initiative* demonstrated improvements in any breast-feeding and EBF rates ${ }^{(75-77)}$. Baby-friendly support, counselling, or education and special training of health staff provided through health facility services had a significant impact on improved EBF (for three interventions, relative risk range $=1 \cdot 33-1 \cdot 66$; 95\% CI $1 \cdot 14,1.92)^{(76)}$. Studies supportive of our findings indicate that inadequate staff knowledge and practices related to breast-feeding, reliance on infant formula and clarification on which circumstances to use formula can contribute to inconsistent breast-feeding information from health facility providers, which needs to be addressed ${ }^{(78,79)}$.

Kangaroo mother care, defined as skin-to-skin care, EBF and supportive care for the mother and baby dyad in health facilities, is also a key intervention for supporting $\mathrm{EBF}^{(80)}$, with evidence of its benefits on EBF rates and neonatal morbidity and mortality ${ }^{(81)}$. In addition, as part of a comprehensive breast-feeding package, a few studies have noted a positive correlation of increased breast-feeding rates in hospitals with human milk banks for vulnerable infants ${ }^{(82-85)}$.

* (i) Have a written breast-feeding policy that is routinely communicated to all health-care staff; (ii) train all health-care staff in skills necessary to implement this policy; (iii) inform all pregnant women about the benefits and management of breast-feeding; (iv) help mothers initiate breastfeeding within a half-hour of birth; (v) show mothers how to breast-feed and how to maintain lactation, even if they are separated from their infants; (vi) give newborn infants no food or drink other than breast milk, unless medically indicated; (vii) practise rooming-in - allow mothers and infants to remain together $24 \mathrm{~h} / \mathrm{d}$; (viii) encourage breast-feeding on demand; (ix) give no artificial teats or pacifiers (also called dummies or soothers) to breast-feeding infants; (x) foster the establishment of breastfeeding support groups and refer mothers to them on discharge from the hospital or clinic.
Strengthening family- and community-level interventions A central finding from the current review is the identified need for improving and sustaining breast-feeding support at the household and community levels. Promotion, counselling and education on EBF in the health facility and community was deemed one of the 'most powerful interventions' examined to improve breast-feeding, showing a $152 \%$ increase in $\mathrm{EBF}^{(76)}$. Counselling as a single intervention in the community or by health staff demonstrated lower effects on EBF, suggesting the importance of linking communities with health facilities to support $\mathrm{EBF}^{(76,78)}$.

Strong implementation of the tenth step of the WHO/ UNICEF 10 Steps of Successful Breast-feeding is a key aspect of sustaining gains in breast-feeding achieved in maternity wards beyond the day of birth, evidenced by the lack of strong breast-feeding outcomes/benefits, often due to weak implementation and support at the community level ${ }^{(79,86-88)}$. Targeted breast-feeding promotion and support by trained clinic personnel in tandem with peer-based counselling for addressing breast-feeding problems is needed. The BabyFriendly Community Initiative expands the tenth step via combination of mother and community support groups and home visits by community health volunteers throughout the first year of life to provide support for $\mathrm{EBF}^{(89)}$. The success of large-scale IYCF programmes lies in the importance of IYCF counselling and community support, in tandem with community awareness ${ }^{(90)}$.

Several randomized controlled trials have demonstrated that community-led interventions, with an attention to quality, content and frequency of counselling, show positive effects on $\mathrm{EBF}^{(91,92)}$. A randomized controlled trial in Kenya found that women who received intensive home-based breast-feeding counselling addressing prevention and management of breast-feeding challenges were more likely to exclusively breast-feed than women who received semi-intensive counselling at a health facility ${ }^{(93)}$. In a cluster-randomized controlled trial carried out in Bangladesh, the implementation of participatory women's groups led to significant increases in EBF for 6 months $(15 \%)$ and mean duration of breast-feeding $(+38 \mathrm{~d})$ in intervention $v$. control areas and pre- $v$. postintervention $^{(92)}$. Similarly, in India, peer counselling through mother support groups showed improved initiation within an hour of birth, EBF and decreased prelacteal feeding at 2 and 5 years post-baseline ${ }^{(94)}$.

The present review also underscores the importance of involvement of family members, who can influence when, what and how babies are fed ${ }^{(6,95)}$. A study in Indonesia demonstrated that multilevel breast-feeding promotion, including individuals, families, communities and health facilities, resulted in a tenfold higher prevalence of EBF at 6 months in the intervention $v$. control group ${ }^{(91)}$.

\section{Strengths and limitations}

The present review has a number of strengths. Inclusion of data sources in multiple languages, including French and 
Spanish, provided a richer analysis than conventional data sources. We also adhered closely to PRISMA guidelines, which provide a rigorous schema for data reporting. Finally, we identified gaps in the literature to inform on future research, programming and policy work.

Many studies included in the review were descriptive or observational and did not explore the associations between noted barriers and EBF. The definition of certain variables, such as inadequate maternal diet, was lacking or not described in depth. In addition, more information is needed on the quality and content of counselling given on EBF within the context of ANC and at the community level.

A major limitation is the lack of information on countrylevel implementation of the International Code of Marketing of Breast-milk Substitutes. Mixed feeding and use of infant formula is common through actions such as free provision in maternity wards and aggressive promotion of these food products ${ }^{(96)}$. Of 136 countries, only about onethird have legislation covering most or all provisions of the Code ${ }^{(79)}$. Effective monitoring and enforcement of national Code legislation is a key challenge, as insufficient laws and lack of sanctions allow for continued Code violations, which are compounded by the lack of political will, lack of coordination among stakeholders, continued intervention from manufacturers and distributors, insufficient data, and limited human and financial resources ${ }^{(79)}$. In Thailand and Cambodia, commercial promotion of breast-milk substitutes and continued provision of formula milk in hospitals continue to negatively impact EBF and contribute to high rates of prelacteal feeding among children 0-5 months of age ${ }^{(97,98)}$. Pervasive marketing to young children continues in the face of restrictive national laws ${ }^{(98)}$.

\section{Conclusion}

To reach the World Health Assembly target of increasing the rate of $\mathrm{EBF}$ in the first 6 months up to at least $50 \%$ by 2025, cultural and health systems barriers that impede EBF should be addressed. Improving knowledge and counselling skills of health workers to address breast-feeding problems and increasing community support for breastfeeding are critical to the success of IYCF programmes. Key actions are needed to support legislation and regulations on marketing of breast-milk substitutes, paid maternity leave and breast-feeding breaks for working mothers in low- and middle-income countries.

\section{Acknowledgements}

Acknowledgements: The authors gratefully acknowledge Sarah Straubinger for aiding with screening articles and Allison Gottwalt editing the manuscript and extraction of qualitative data from papers included in this review. Financial support: This work is made possible by the generous support of the American people through the US Agency for International Development (USAID) under the terms of the Cooperative Agreement AID-OAA-A-1400028. Conflict of interest: None. Authorship: J.A.K. formulated the research question and directed the systematic literature review. E.L. and H.D. carried out the literature review and compilation of data, with input from J.A.K. J.A.K., E.L., H.D. and C.E. jointly wrote the manuscript. All authors reviewed and approved the final manuscript. Ethics of buman subject participation: Not applicable.

\section{References}

1. Victora CG, Bahl R, Barros AJ et al. (2016) Breastfeeding in the 21st century: epidemiology, mechanisms, and lifelong effect. Lancet 387, 475-490.

2. UNICEF \& World Health Organization (2009) Baby-Friendly Hospital Initiative: Revised, Updates and Expanded for Integrated Care. Geneva: WHO.

3. Black RE, Allen LH, Bhutta ZA et al. (2008) Maternal and child undernutrition: global and regional exposures and health consequences. Lancet 371, 243-260.

4. International Food Policy Research Institute (2015) Global Nutrition Report 2015: Actions and Accountability to Advance Nutrition \& Sustainable Development. Washington, DC: IFPRI.

5. International Food Policy Research Institute (2016) Global Nutrition Report 2016: From Promise to Impact: Ending Malnutrition by 2030. Washington, DC: IFPRI.

6. UNICEF (2016) From the First Hour of Life: Making the Case for Improved Infant and Young Child Feeding Everywhere. Part I: Focus on Breastfeeding. New York: UNICEF.

7. Kavle JA, Mehanna S, Saleh G et al. (2015) Exploring why junk foods are 'essential' foods and how culturally tailored recommendations improved feeding in Egyptian children. Matern Child Nutr 11, 346-370.

8. World Health Organization (2016) Global Targets 2025: To improve maternal, infant and young child nutrition. http://www.who.int/nutrition/global-target-2025/en/ (accessed September 2016).

9. US Agency for International Development (2016) Acting on the Call. Ending Preventable Child and Maternal Deaths: A Focus on Equity. Washington, DC: USAID.

10. Critical Appraisal Skills Programme (2013) 10 questions to help you make sense of a review. http://www.media.wix. com/ugd/dded87_a02ff2e3445f4952992d5a96ca562576.pdf (accessed September 2016).

11. Chandrashekhar TS, Joshi HS, Binu VS et al. (2007) Breast-feeding initiation and determinants of exclusive breast-feeding - a questionnaire survey in an urban population of western Nepal. Public Health Nutr 10, 192-197.

12. Egata G, Berhane Y \& Worku A (2013) Predictors of nonexclusive breastfeeding at 6 months among rural mothers in east Ethiopia: a community-based analytical cross-sectional study. Int Breastfeed J $\mathbf{8}, 8$.

13. Mahmood SE, Srivastava A, Shrotriya VP et al. (2012) Infant feeding practices in the rural population of north India. J Family Community Med 19, 130-135.

14. Matovu A, Kirunda B, Rugamba-Kabagambe G et al. (2008) Factors influencing adherence to exclusive breast feeding among HIV positive mothers in Kabarole District, Uganda. East Afr Med J 85, 162-170.

15. Tiwari R, Mahajan PC \& Lahariya C (2009) The determinants of exclusive breast feeding in urban slums: a community based study. J Trop Pediatr 55, 49-54. 
16. Ugboaja JO, Berthrand NO, Igwegbe AO et al. (2013) Barriers to postnatal care and exclusive breastfeeding among urban women in southeastern Nigeria. Niger Med J 54, 45-50.

17. Joshi PC, Angdembe MR, Das SK et al. (2014) Prevalence of exclusive breastfeeding and associated factors among mothers in rural Bangladesh: a cross-sectional study. Int Breastfeed J 9, 7.

18. Ogunlesi TA (2010) Maternal socio-demographic factors influencing the initiation and exclusivity of breastfeeding in a Nigerian semi-urban setting. Matern Child Health J 14, 459-465.

19. Onah S, Osuorah DIC, Ebenebe J et al. (2014) Infant feeding practices and maternal socio-demographic factors that influence practice of exclusive breastfeeding among mothers in Nnewi South-East Nigeria: a cross-sectional and analytical study. Int Breastfeed J 9, 6.

20. Susiloretni KA, Krisnamurni S, Sunarto et al. (2013) The effectiveness of multilevel promotion of exclusive breastfeeding in rural Indonesia. Am J Health Promot 28, e44-e55.

21. Setegn T, Belachew T, Gerbaba M et al. (2012) Factors associated with exclusive breastfeeding practices among mothers in Goba district, south east Ethiopia: a crosssectional study. Int Breastfeed J 7, 17.

22. Tamiru D, Belachew T, Loha E et al. (2012) Sub-optimal breastfeeding of infants during the first six months and associated factors in rural communities of Jimma Arjo Woreda, Southwest Ethiopia. BMC Public Health 12, 363.

23. Maonga AR, Mahande MJ, Damian DJ et al. (2016) Factors affecting exclusive breastfeeding among women in Muheza District Tanga Northeastern Tanzania: a mixed method community based study. Matern Child Health J 20, 77-87.

24. Babakazo P, Donnen P, Akilimali P et al. (2015) Predictors of discontinuing exclusive breastfeeding before six months among mothers in Kinshasa: a prospective study. Int Breastfeed J 10, 19.

25. Khanal V, Lee AH, Karkee R et al. (2015) Postpartum breastfeeding promotion and duration of exclusive breastfeeding in Western Nepal. Birth 42, 329-336.

26. Diagne-Guéye NR, Diack-Mbaye A, Dramé M et al. (2011) Knowledge and practices of Senegalese mothers living in rural or suburban area on children feeding from birth to six months of age. J Pediatr Pueric 24, 161-166.

27. Yotebieng M, Chalachala JL, Labbok M et al. (2013) Infant feeding practices and determinants of poor breastfeeding behavior in Kinshasa, Democratic Republic of Congo: a descriptive study. Int Breastfeed J 8, 11.

28. Haider R, Rasheed S, Sanghvi TG et al. (2010) Breastfeeding in infancy: identifying the program-relevant issues in Bangladesh. Int Breastfeed J 5, 21.

29. Arusei RJ, Ettyang GA \& Esamai F (2011) Feeding patterns and growth of term infants in Eldoret, Kenya. Food Nutr Bull 32, 307-314.

30. Aluko-Arowolo S \& Adekoya JA (2012) Exclusive breastfeeding in the contexts of socio-cultural challenges and mothers' health in rural and mixed urban areas of Ijebu, South Western Nigeria. Gender Behav 10, 4657-4677.

31. Adeyinka T, Ajibola F, Oyesoji A et al. (2008) A hospitalbased assessment of breast-feeding behaviour and practices among nursing mothers in Nigeria and Ghana. PakJ Nutr 7, $165-171$.

32. Sohag AA \& Memon S (2011) Perception, practices and factors associated with exclusive breast feeding failure. Med Channel 17, 100-102.

33. Otoo GE, Lartey AA \& Pérez-Escamilla R (2009) Perceived incentives and barriers to exclusive breastfeeding among periurban Ghanaian women. J Hum Lact 25, 34-41.

34. Seid AM, Yesuf ME \& Koye DN (2013) Prevalence of exclusive breastfeeding practices and associated factors among mothers in Bahir Dar city, Northwest Ethiopia: a communitybased cross-sectional study. Int Breastfeed J 8, 14.

35. Okanda JO, Borkowf CB, Girde S et al. (2014) Exclusive breastfeeding among women taking HAART for PMTCT of HIV-1 in the Kisumu Breastfeeding Study. BMC Pediatr 14, 280.

36. Kamudoni $\mathrm{P}$, Maleta K, Shi $\mathrm{Z}$ et al. (2007) Infant feeding practices in the first 6 months and associated factors in a rural and semiurban community in Mangochi District, Malawi. J Hum Lact 23, 325-332.

37. Sharma M \& Kanani S (2006) Grandmothers' influence on child care. Indian J Pediatr 73, 295-298.

38. Ssenyonga R, Muwonge R \& Nankya I (2004) Towards a better understanding of exclusive breastfeeding in the era of HIV/AIDS: a study of prevalence and factors associated with exclusive breastfeeding from birth, in Rakai, Uganda. J Trop Pediatr 50, 348-353.

39. Kishore MSS, Kumar P \& Aggarwal AK (2009) Breastfeeding knowledge and practices amongst mothers in a rural population of North India: a community-based study. J Trop Pediatr 55, 183-188.

40. Ukegbu AU, Ukegbu PO, Onyeonoro UU et al. (2011) Determinants of breastfeeding patterns among mothers in Anambra State, Nigeria. East Afr J Public Health 8, 226-231.

41. Kimani-Murage EW, Madise NJ, Fotso JC et al. (2011) Patterns and determinants of breastfeeding and complementary feeding practices in urban informal settlements, Nairobi Kenya. BMC Public Health 11, 396.

42. Karkee R, Lee AH, Khanal V et al. (2014) A communitybased prospective cohort study of exclusive breastfeeding in central Nepal. BMC Public Health 14, 927.

43. Raghavan V, Bharti B, Kumar P et al. (2014) First hour initiation of breastfeeding and exclusive breastfeeding at six weeks: prevalence and predictors in a tertiary care setting. Indian J Pediatr 81, 743-750.

44. Meshram II, Laxmaiah A, Venkaiah K et al. (2012) Impact of feeding and breastfeeding practices on the nutritional status of infants in a district of Andhra Pradesh, India. Natl Med J India 25, 201-206.

45. Engebretsen IMS, Moland KM, Nankunda J et al. (2010) Gendered perceptions on infant feeding in Eastern Uganda: continued need for exclusive breastfeeding support. Int Breastfeed J 5, 13.

46. Cherop CE, Keverenge-Ettyang AG \& Mbagaya GM (2009) Barriers to exclusive breastfeeding among infants aged 0-6 months in Eldoret municipality, Kenya. East Afr J Public Health 6, 69-72.

47. Obilade TT (2015) The knowledge, attitude and practice of exclusive breastfeeding among mothers in two semi-urban areas around a Baby Friendly Hospital Initiative (BFHI) designated hospital in Lagos State, Nigeria. Int Arch Med 8, available at http://dx.doi.org/10.3823/1614

48. Olayemi O, Aimakhu CO, Bello FA et al. (2007) The influence of social support on the duration of breast-feeding among antenatal patients in Ibadan. J Obstet Gynaecol 27, 802-805.

49. Safari JG, Kimambo SC \& Lwelamira JE (2013) Feeding practices and nutritional status of infants in Morogoro municipality, Tanzania. Tanzan J Health Res 15, 178-185.

50. Kimani-Murage EW, Wekesah F, Wanjohi M et al. (2015) Factors affecting actualisation of the WHO breastfeeding recommendations in urban poor settings in Kenya. Matern Child Nutr 11, 314-332.

51. Gewa CA, Oguttu M \& Savaglio L (2011) Determinants of early child-feeding practices among HIV-infected and noninfected mothers in rural Kenya. J Hum Lact 27, 239-249.

52. Afiyanti Y \& Juliastuti D (2012) Exclusive breastfeeding practice in Indonesia. Br J Midwifery 20, 484-491.

53. Suresh S, Sharma KK, Saksena M et al. (2014) Predictors of breastfeeding problems in the first postnatal week and its 
effect on exclusive breastfeeding rate at six months: experience in a tertiary care centre in Northern India. Indian J Public Health 58, 270-273.

54. Østergaard LR \& Bula A (2010) They call our children 'Nevirapine babies?': a qualitative study about exclusive breastfeeding among HIV positive mothers in Malawi. Afr J Reprod Health 14, 213-222.

55. Maman S, Cathcart R, Burkhardt G et al. (2012) The infant feeding choices and experiences of women living with HIV in Kinshasa, Democratic Republic of Congo. AIDS Care 24, 259-265.

56. Webb-Girard A, Cherobon A, Mbugua S et al. (2012) Food insecurity is associated with attitudes towards exclusive breastfeeding among women in urban Kenya. Matern Child Nutr 8, 199-214.

57. Aubel J, Touré I \& Diagne M (2004) Senegalese grandmothers promote improved maternal and child nutrition practices: the guardians of tradition are not averse to change. Soc Sci Med 59, 945-959.

58. Balogun OO, Dagvadorj A, Anigo KM et al. (2015) Factors influencing breastfeeding exclusivity during the first 6 months of life in developing countries: a quantitative and qualitative systematic review. Matern Child Nutr 11, 433-451.

59. Bevan G \& Brown M (2014) Interventions in exclusive breastfeeding: a systematic review. Br J Nurs 23, 86-89.

60. Asemahagn MA (2016) Determinants of exclusive breastfeeding practices among mothers in Azezo district, northwest Ethiopia. Int Breastfeed J 11, 22.

61. Mascarenhas ML, Albernaz EP, Silva MB et al. (2006) Prevalence of exclusive breastfeeding and its determiners in the first 3 months of life in the South of Brazil. J Pediatr 82, 289-294.

62. Nyanga NM, Musita C, Otieno A et al. (2012) Factors influencing knowledge and practice of exclusive breastfeeding in Nyando district, Kenya. Afr J Food Agric Nutr Dev 12, 6633-6645.

63. Mlay RS, Keddy B \& Stern PN (2004) Demands out of context: Tanzanian women combining exclusive breastfeeding with employment. Health Care Women Int 25, 242-254.

64. Dun-Dery EJ \& Laar AK (2016) Exclusive breastfeeding among city-dwelling professional working mothers in Ghana. Int Breastfeed J 11, 23.

65. Soomro JA, Shaikh ZN, Saheer TB et al. (2016) Employers' perspective of workplace breastfeeding support in Karachi, Pakistan: a cross-sectional study. Int Breastfeed J 11, 24.

66. World Health Organization (2015) World Breastfeeding Week: 1-7 August 2015. Infographics. http://www.who. $\mathrm{int} /$ mediacentre/events/meetings/2015/world-breastfeedingweek/en/ (accessed September 2016).

67. World Alliance for Breastfeeding Action (2008) Maternity Protection Campaign Kit, 2nd ed. Malaysia: Jutaprint.

68. International Labour Organization (2010) Maternity at Work: A Review of National Legislation, 2nd ed. Geneva: ILO.

69. Prior E, Santhakumaran S, Gale C et al. (2012) Breastfeeding after cesarean delivery: a systematic review and metaanalysis of world literature. Am J Clin Nutr 95, 1113-1135.

70. Ahluwalia IB, Li R \& Morrow B (2012) Breastfeeding practices: does method of delivery matter? Matern Child Health J 16, 231-237.

71. Zanardo V, Svegliado G, Cavallin F et al. (2010) Elective cesarean delivery: does it have a negative effect on breastfeeding? Birth 37, 275-279.

72. Chapman DJ (2014) Maternal perception of breastfeeding challenges after cesarean delivery. J Hum Lact 30, 394-395.

73. Fein SB, Mandal B \& Roe BE (2008) Success of strategies for combining employment and breastfeeding. Pediatrics 122, Suppl. 2, S56-S62.

74. World Health Organization (2016) WHO Recommendations on Antenatal Care for a Positive Pregnancy Experience. Geneva: WHO.
75. Sinha B, Chowdhury R, Sankar MJ et al. (2015) Interventions to improve breastfeeding outcomes: a systematic review and meta-analysis. Acta Paediatr 104, 114-134.

76. Pérez-Escamilla R (2016) The Mexican dietary and physical activity guidelines: moving public nutrition forward in a globalized world. J Nutr 146, issue 9, 1924S-1927S.

77. Ojofeitimi EO, Esimai OA, Owolabi OO et al. (2000) Breast feeding practices in urban and rural health centres: impact of baby friendly hospital initiative in Ile-Ife, Nigeria. Nutr Health 14, 119-125.

78. Semenic S, Childerhose JE, Lauzière J et al. (2012) Barriers, facilitators, and recommendations related to implementing the Baby-Friendly Initiative (BFI): an integrative review. J Hum Lact 28, 317-334.

79. World Health Organization (2016) Marketing of Breast-milk Substitutes: National Implementation of the International Code. Status Report 2016. Geneva: WHO.

80. Engmann C, Wall S, Darmstadt G et al. (2013) Consensus on kangaroo mother care acceleration. Lancet 382, e26-e27.

81. Conde-Agudelo A \& Díaz-Rossello JL (2016) Kangaroo mother care to reduce morbidity and mortality in low birthweight infants. Cochrane Database Syst Rev 8, CD002771.

82. Bertino E, Giuliani F, Baricco M et al. (2013) Benefits of donor milk in the feeding of preterm infants. Early Hum Dev 89, Suppl. 2, S3-S6.

83. Fugate K, Hernandez I, Ashmeade T et al. (2015) Improving human milk and breastfeeding practices in the NICU. J Obstet Gynecol Neonatal Nurs 44, 426-438.

84. Parker MG, Burnham L, Mao W et al. (2016) Implementation of a donor milk program is associated with grater consumption of mothers' own milk among VLBW infants in a US, level 3 NICU. J Hum Lact 32, 221-228.

85. DeMarchis A, Israel-Ballard K, Mansen KA et al. (2017) Establishing an integrated human milk banking approach to strengthen newborn care. J Perinatol 37, 469-474.

86. Taddei JA, Westphal MF, Venancio S et al. (2000) Breastfeeding training for health professionals and resultant changes in breastfeeding duration. Sao Paulo Med J 118, 185-191.

87. Kramer MS, Chalmers B, Hodnett ED et al. (2001) Promotion of Breastfeeding Intervention Trial (PROBIT): a randomized trial in the Republic of Belarus. JAMA $\mathbf{2 8 5}$, 413-420.

88. Coutinho SB, de Lira PI, de Carvalho Lima M et al. (2005) Comparison of the effect of two systems for the promotion of exclusive breastfeeding. Lancet 366, 1094-1100.

89. Kenya Ministry of Health, USAID Maternal and Child Survival Program, UNICEF (2016) Baby Friendly Community Initiative: Implementation Guidelines. Nairobi: Kenya $\mathrm{MOH}$.

90. Baker J, Sanghvi T, Hajeebhoy N et al. (2013) Using an evidence-based approach to design large-scale programs to improve infant and young child feeding. Food Nutr Bull 34, 3 Suppl., S146-S155.

91. Sikander S, Maselko J, Zafar S et al. (2015) Cognitivebehavioral counseling for exclusive breastfeeding in rural pediatrics: a cluster RCT. Pediatrics 135, e424-e 431.

92. Younes L, Houweling TAJ, Azad K et al. (2015) The effect of participatory women's groups on infant feeding and child health knowledge, behaviour and outcomes in rural Bangladesh: a controlled before-and-after study. J Epidemiol Community Health 69, 374-381.

93. Ochola SA, Labadarios D \& Nduati RW (2013) Impact of counselling on exclusive breast-feeding practices in a poor urban setting in Kenya: a randomized controlled trial. Public Health Nutr 16, 1732-1740.

94. Kushwaha KP, Sankar J, Sankar ML et al. (2014) Effect of peer counselling by mother support groups on infant and 
young child feeding practices: the Lalitpur experience. PLoS One 9, e109181.

95. Negin J, Coffman J, Vizintin P et al. (2016) The influence of grandmothers on breastfeeding rates: a systematic review. BMC Pregnancy Childbirth 16, 91.

96. Piwoz EG \& Huffman SL (2015) The impact of marketing of breast-milk substitutes on WHO-recommended breastfeeding practices. Food Nutr Bull 36, 373-386.
97. Thepha T, Marais D, Bell J et al. (2017) Facilitators and barriers to exclusive breastfeeding in Thailand: a narrative review. J Community Public Health Nurs 3, 160-168.

98. Pries AM, Huffman SL, Mengkheang et al. (2016) Pervasive promotion of breastmilk substitutes in Phnom Penh, Cambodia, and high usage by mothers for infant and young child feeding. Matern Child Nutr 12, $38-51$. 